\title{
Quality and antioxidant properties of jelly supplemented with apricot juice concentrate
}

\author{
Jun Ho Lee*, So Yeon Kim \\ Department of Food Engineering, Daegu University, Gyeongsan 38453, Korea
}

\begin{abstract}
Gummy jellies are becoming more popular than in the past as a dessert or snack in the Korean food market. Taking advantages of diverse functional activities of apricot juice concentrate (AJC), it can be incorporated into snack food such as jelly to meet consumers' emerging demands regarding health concerns. However, there has been a scarcity of reports on the most appropriate concentration of AJC in jellies. This prompted us to undertake the present investigation with the objective to evaluate the physical, sensory, and antioxidant characteristics of jellies containing various concentrations of $\mathrm{AJC}(7.5 \%, 15 \%, 22.5 \%$, and $30 \%)$. The $\mathrm{pH}$, moisture content, and lightness $\left(L^{*}\right)$ decreased significantly while total soluble solids (TSS), hardness, redness $\left(a^{*}\right)$, and yellowness $\left(b^{*}\right)$ increased significantly with increasing concentrations AJC (p<0.05). In addition, the 2,2-diphenyl-1-picrylhydrazyl (DPPH) and 2,2'-azino-bis-3-ethylbenzothiazoline-6-sulfonic acid (ABTS) radical scavenging activities significantly increased $(\mathbf{p}<0.05)$ at higher AJC concentrations. A consumer acceptance test indicated that the incorporation of $22.5 \% \mathrm{AJC}$ had favorable effects on consumer preferences for all the tested attributes. Based on our study, jelly incorporated with $22.5 \%$ AJC is recommended for developing AJC-supplemented jellies with improved overall qualities without sacrificing consumer acceptability and while taking advantage of the functional properties of AJC.
\end{abstract}

Keywords : apricot juice concentrate, jelly, physicochemical properties, consumer acceptance, antioxidant properties

\section{Introduction}

Apricot (Prunus armeniaca L.) is a branch of deciduous glaucoma belonging to the rose family, native to eastern Asia and widely cultivated in Korea, China, and Japan $(1,2)$. The fruit has a pleasant aroma which encourages its consumption worldwide (3). Apricots are a rich source of sugars, fibers, minerals, and vitamins (4). In addition, they contain appreciable amounts of carotenoids (mainly beta-carotene), polyphenols, fatty acids, and polysaccharides, and have been shown to exert various biological activities that are beneficial to human health (5).

Although apricots are considered as one of the most promising functional foods due to the crucial constituents (such as dietary fiber, sorbitol, potassium, copper, and

*Corresponding author. E-mail : leejun@daegu.ac.kr Phone : 82-53-850-6531, Fax : 82-53-850-6539

Received 29 April 2019; Revised 11 June 2019; Accepted 14 June 2019.

Copyright (c) The Korean Society of Food Preservation. All rights reserved. phenolic compounds) which contribute to many aspects of human health (6), they are one of the least studied functional foods. Apricot juice, apricot juice concentrate (AJC), and apricot juice powder have been used limitedly in recent studies to improve the quality of muffins (2), cookies (6), tofu (7), suggidduk (8-10), and haengbyeong (11). The development of new types of food supplemented with AJC could be useful for consumers with health concerns.

Gummy jellies are a widely consumed dessert or snack, and are popular with various age groups due to their texture and ease of cooking $(12,13)$. Jellies are prepared with concentrated sugar solutions, gelling agents, and other minor ingredients (coloring, acid, and flavoring agents) (14). The raw material is first gelatinized by heating, mixing with acids, coloring, and flavoring, after which the molten product is formed in molds of different sizes and shapes (15). The market share of jelly products had dramatically increased from 68 billion Won in 2014 to 202 billion Won in 2020, which is likely due to new and unique products emerging in the market and appealing to 20-30-year old consumers (16).

A review indicated that various concentrates, such as black 
ginseng (17), Rehmannia radix (18), purple sweet potato (19), cranberry (20), and corn (13) concentrates have been successfully used in jelly manufacturing. Nevertheless, little information is available regarding the effects of AJC on the physicochemical and sensory properties of gummy jellies.

In this study, AJC was supplemented with water to improve its functional and nutritional value. Therefore, the aim of this research was to determine the effects of the incorporation of different concentrations of AJC (7.5-30\%) on the physical and sensory characteristics of jellies. The antioxidant properties of AJC-supplemented jellies were also determined.

\section{Materials and methods}

\section{Jelly materials}

Commercial grade AJC (Korea F\&B Corp., Chungbuk, Korea), gelatin (Samwon, Daegu, Korea), and sugar (CJ, Seoul, Korea) were purchased from a local market. The relevant characteristics of AJC were determined as follows: $\mathrm{pH}=5.64$, soluble solids content $=3.06{ }^{\circ} \mathrm{Brix}, \mathrm{L}^{*}$-value $=$ $27.01, \mathrm{a}^{*}$-value $=17.95$, and $\mathrm{b}^{*}$-value $=25.09$. This concentrate contained purified water, white sugar, fructose, citric acid, and sodium citrate as indicated by the manufacturer. All ingredients are generally recognized as safe (GRAS).

\section{Preparation of jellies}

The appropriate concentration of AJC varied depending on the model food system investigated. Several preliminary experiments using various AJC concentration in the formulation were conducted. The addition of $\leq 30 \%$ AJC seemed appropriate based on the quality of apricot jellies checked by the principal investigators. Finally, the test jelly samples were prepared by supplementing the standard jelly recipe with $0 \%, 7.5 \%, 15 \%, 22.5 \%$, and $30 \%$ AJC.

The standard jelly recipe was used for the control and consisted of $400 \mathrm{~mL}$ of water, $30 \mathrm{~g}$ of white granulated sugar, and $10 \mathrm{~g}$ of gelatin. First, sugar $(30 \mathrm{~g})$ was dissolved in boiling water $(200 \mathrm{~mL})$ for $4 \mathrm{~min}$, followed by $200 \mathrm{~mL}$ of water with dissolved gelatin (10 g) for $2 \mathrm{~min}$, after which the appropriate amount of AJC was incorporated. The final mixture was covered and boiled for $4 \mathrm{~min}$. The mixture was then immediately poured into molds and allowed to cool for $30 \mathrm{~min}$ at room temperature, after which samples were refrigerated at $4^{\circ} \mathrm{C}$ for $3 \mathrm{~h}$ prior to experiments. The samples were warmed at room temperature prior to each analysis.

\section{Physical analysis}

Ten grams of sample mixed with $90 \mathrm{~mL}$ of distilled water was prepared to measure the $\mathrm{pH}$ of jelly samples using a pH meter (MP230, Mettler Toledo, Schwerzenbach, Switzerland) at room temperature. The same samples were used to determine total soluble solids (TSS; expressed in ${ }^{\circ}$ Brix), using an Atago refractometer (PR-201, Atago Co., LTD, Tokyo, Japan). The moisture content was determined by drying pre-weighed amounts of samples to a constant weight at $105^{\circ} \mathrm{C}$ in an oven for $24 \mathrm{~h}$. All measurements were repeated five times, and mean values were compared.

Color was measured in terms of $\mathrm{L}^{*}, \mathrm{a}^{*}$, and $\mathrm{b}^{*} \mathrm{CIE}$ values using a Minolta Spectrophotometer (CM-600d, Minolta Co., Osaka, Japan) equipped with a D65 standard illuminant, an 8-mm aperture, and a $10^{\circ}$ standard observer. The spectrophotometer was calibrated with a standard white calibration cap supplied by the manufacturer. Color was measured at the same location (six sides of each cube) using five jelly cubes $(3 \times 3 \times 3 \mathrm{~cm})$ for each treatment.

Textural characteristics were evaluated by $30 \%$ compression of the individual samples $(3 \times 3 \times 3 \mathrm{~cm})$ with a computer-controlled Advanced Universal Testing System (LRXPlus, Lloyd Instrument Limited, Fareham, Hampshire, $\mathrm{UK}$ ) at room temperature with a 5-cm-diameter stainless-steel disc probe. The crosshead speed was $1 \mathrm{~mm} / \mathrm{s}$. Fifteen samples for each replication were tested, and their mean values were compared.

\section{Antioxidant analysis}

The 2,2-diphenyl-1-picrylhydrazyl (DPPH)-radical scavenging activities of samples were measured in terms of their hydrogen-donating or DPPH radical scavenging activity. The assay was performed as previously described by Brand-Williams et al. (21) with some modifications. Briefly, $0.2 \mathrm{mM}$ solution of DPPH radical in ethanol was prepared, after which $5 \mathrm{~mL}$ of this solution was added to $1 \mathrm{~mL}$ of sample solution in ethanol at different concentrations. The solution was then shaken and left to stand for $10 \mathrm{~min}$. Decolorization of the DPPH-donated protons was determined by measuring the absorbance at $517 \mathrm{~nm}$ using a spectrophotometer (Optizen 2020 UV Plus, Mecasys Co., Ltd., Daejeon, Korea). The DPPH radical scavenging activity was calculated using the following equation:

Radical scavenging activity $(\%)=$

$$
\left[\left(A b s_{\text {. control }}-A b s_{\text {sample }}\right) / A b s_{\text {.control }}\right] \times 100
$$


Spectrophotometric analysis of the 2,2'-azino-bis-3ethylbenzothiazoline-6-sulfonic acid (ABTS) ${ }^{+}$. radical scavenging activity was carried out according to the method used by $\mathrm{Re}$ et al. (22) with slight modifications. The assay is based on the ability of antioxidants to reduce $\mathrm{ABTS}^{+}$. (blue/green) for the generation of $\mathrm{ABTS}^{-2}$ (colorless). Briefly, the $\mathrm{ABTS}^{+}$. cation radical was produced by a reaction between $7.4 \mathrm{mM}$ ABTS in $\mathrm{H}_{2} \mathrm{O}$ and $2.6 \mathrm{mM}$ potassium persulfate during storage in the dark at room temperature for 12-16 h. Before use, the $\mathrm{ABTS}^{+}$. solution was diluted with methanol to obtain an absorbance of $1.10 \pm 0.02$ at $734 \mathrm{~nm}$. Subsequently, $3 \mathrm{~mL}$ of the $\mathrm{ABTS}^{+}$. solution was added to $0.1 \mathrm{~mL}$ of the sample. After $10 \mathrm{~min}$, the percent inhibition at $734 \mathrm{~nm}$ was calculated for each concentration relative to blank absorbance.

\section{Sensory analysis}

The AJC-supplemented jellies were evaluated by 50 consumer panelists ( 9 males and 41 females), consisting of undergraduate and graduate students, who had an interest and volunteered for the participation. Five samples were presented in random order and panelists were asked to evaluate consumer attributes of color, aroma, taste, texture, and overall acceptability. Panelists were asked to evaluate preference levels using a nine-point hedonic scale ( $9=$ like extremely, $5=$ neither like nor dislike, and $1=$ dislike extremely). Each AJC-supplemented jelly sample $(3 \times 3 \times 3 \mathrm{~cm})$ was randomly coded using a three-digit number. Panelist received a tray containing the samples, a glass of water, and an evaluation sheet and were advised to rinse their palates between samples to minimize residual flavor effects. Enough space was given to handle the samples and the questionnaire, and the evaluation time was not constrained. No specific compensation was given to the participants.

This study was approved by the Daegu University Institutional Review Board (IRB \# 1040621-201711HR-018-002).

\section{Statistical analysis}

Statistical analysis was carried out using the SAS for Windows version 9.1 (SAS Inst. Inc., Cary, NC, USA). Results were expressed as mean values with the corresponding standard deviation, and significant differences were compared with Duncan's multiple range test at a 5\% level of significance.

\section{Results and discussion}

\section{Physical characteristics}

Table 1 describes the physical characterization of the jellies supplemented with different levels of AJC. The $\mathrm{pH}$ in jellies ranged from 5.65 to 6.62 and decreased upon addition of an increasing amount of AJC $(\mathrm{p}<0.05)$. Similar reductions of $\mathrm{pH}$ have been observed in jellies incorporated with corn (13) and jujube (23) concentrate, which is likely due to the weak acidic nature of the supplemented concentrate.

Moisture contents of samples ranged from 72.15 to $86.84 \%$ (w.b.), and the control sample exhibited the highest moisture content. This range is in good accordance with the moisture content of jellies incorporated with corn concentrate (80.06-89.34\%) (13) and jujube concentrate (79.56-84.35\%) (23), where similar decreasing trends were reported with the addition of higher amounts of both supplements. However, other studies have reported slightly lower moisture contents due to the formulation of different ingredients and additives. Moisture contents ranged from 59.37-62.23\% and 65.22-74.81\% for jellies incorporated with Rehmannia radix concentrate (18) and Gastrodia elata concentrate (24), respectively, and TSS increased significantly with an increasing AJC concentration $(\mathrm{p}<0.05)$ (Table 1). This result is likely to be attributable to the addition of soluble solids from AJC, which showed a TSS of $3.06{ }^{\circ}$ Brix. Similar results were reported for jellies supplemented with corn concentrate (13).

Texture analyses found that the hardness of jellies increased significantly as the AJC concentration increased $(\mathrm{p}<0.05)$ hardness of jellies ranging from $3.64 \mathrm{~N}$ at $0 \%$ addition to $6.58 \mathrm{~N}$ at $30 \%$ addition. The higher hardness of jellies containing a higher amount of AJC could be attributed to a lower water holding capacity (19) as well as a lower moisture content. A similar result was reported for jellies incorporated with corn concentrate (13) and black ginseng concentrate (17).

Surface color is a very important element determining initial consumer acceptability. Jellies with added AJC showed significantly different surface color values compared to the control $(\mathrm{p}<0.05)$. $\mathrm{L}^{*}$-values decreased significantly with increase in the concentration of AJC $(\mathrm{p}<0.05)$. On the other hand, $\mathrm{a}^{*}$ - and $\mathrm{b}^{*}$-values showed reverse trends $(\mathrm{p}<0.05)$; as the concentration of AJC in the formulation increased, jellies became darker and more reddish and yellowish (Fig. 1). These results are in accordance with the findings reported for jellies 
Table 1. Physical properties of jelly incorporated with different concentrations of apricot juice concentrate (AJC)

\begin{tabular}{|c|c|c|c|c|c|c|}
\hline \multirow{2}{*}{\multicolumn{2}{|c|}{ Property }} & \multicolumn{5}{|c|}{$\operatorname{AJC}(\%)$} \\
\hline & & 0 & 7.5 & 15 & 22.5 & 30 \\
\hline \multicolumn{2}{|c|}{$\mathrm{pH}$} & $6.62 \pm 0.06^{\mathrm{a}}$ & $6.27 \pm 0.05^{b}$ & $6.05 \pm 0.02^{c}$ & $5.83 \pm 0.15^{\mathrm{d}}$ & $5.65 \pm 0.04^{e}$ \\
\hline \multicolumn{2}{|c|}{ Moisture content (\%) } & $86.84 \pm 0.21^{\mathrm{a}}$ & $84.65 \pm 0.26^{b}$ & $82.28 \pm 0.19^{c}$ & $77.52 \pm 0.19^{d}$ & $72.15 \pm 0.48^{\mathrm{e}}$ \\
\hline \multicolumn{2}{|c|}{ Total soluble solids ( ${ }^{\circ}$ Brix) } & $0.92 \pm 0.08^{\mathrm{e}}$ & $1.24 \pm 0.05^{\mathrm{d}}$ & $1.46 \pm 0.05^{\mathrm{c}}$ & $1.74 \pm 0.05^{\mathrm{b}}$ & $2.00 \pm 0.07^{\mathrm{a}}$ \\
\hline \multicolumn{2}{|c|}{ Hardness $(\mathrm{N})$} & $3.64 \pm 0.15^{\mathrm{e}}$ & $3.86 \pm 0.21^{\mathrm{d}}$ & $4.35 \pm 0.41^{\mathrm{c}}$ & $5.65 \pm 0.33^{\mathrm{b}}$ & $6.58 \pm 0.27^{\mathrm{a}}$ \\
\hline \multirow{3}{*}{ Color } & $L^{*}$ & $38.37 \pm 0.35^{\mathrm{a}}$ & $31.21 \pm 0.92^{\mathrm{b}}$ & $31.06 \pm 0.61^{b}$ & $30.50 \pm 1.03^{b}$ & $29.28 \pm 0.72^{\mathrm{c}}$ \\
\hline & $a^{*}$ & $-1.48 \pm 0.02^{\mathrm{e}}$ & $6.14 \pm 0.25^{\mathrm{d}}$ & $7.52 \pm 0.15^{\mathrm{c}}$ & $9.78 \pm 0.11^{\mathrm{b}}$ & $14.58 \pm 0.31^{\mathrm{a}}$ \\
\hline & $b^{*}$ & $5.86 \pm 0.12^{\mathrm{e}}$ & $10.63 \pm 0.71^{\mathrm{d}}$ & $13.45 \pm 0.44^{\mathfrak{c}}$ & $16.03 \pm 0.59^{b}$ & $20.44 \pm 0.63^{\mathrm{a}}$ \\
\hline
\end{tabular}

Means within the same row with a different letter $(\mathrm{a}-\mathrm{e})$ are significantly different $(\mathrm{p}<0.05)$.

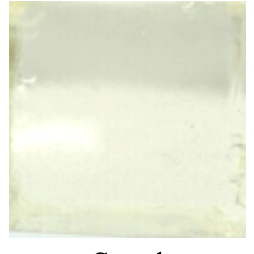

Control

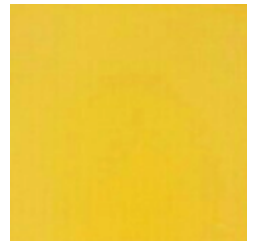

$7.5 \%$

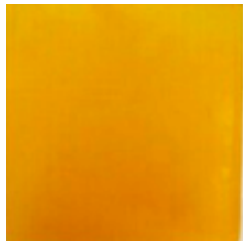

$15 \%$

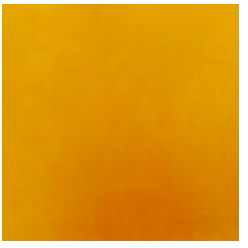

$22.5 \%$

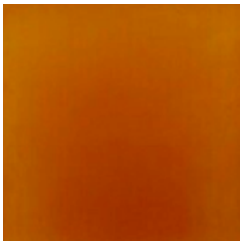

$30 \%$

Fig. 1. Appearance of jellies with different concentrations of apricot juice concentrate (AJC).

supplemented with corn concentrate (13). These results suggest that the color of jellies can be easily controlled based on the concentration of AJC according to consumer and/or manufacturer preferences.

\section{Free radical scavenging activities}

Antioxidant activities were investigated based on DPPH radical scavenging activity and ABTS radical cation assay. The addition of AJC in the jelly formulation enhanced antioxidant activities (Fig. 2), which can be attributed to

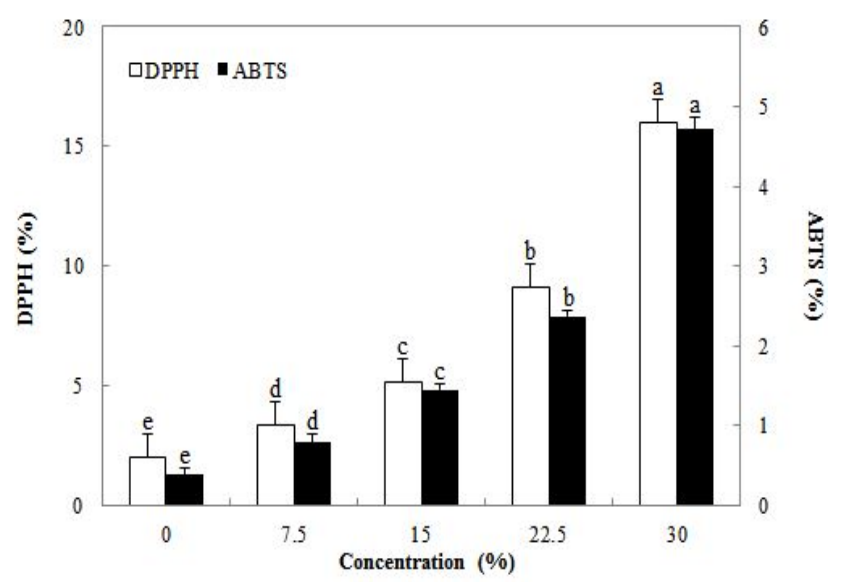

Fig. 2. DPPH and ABTS radical scavenging activities of jellies with different concentrations of apricot juice concentrate (AJC).

Means within the same activity with a different letter $(a-e)$ are significantly different $(p<0.05)$. the abundant antioxidant capacities of AJC. There were significant increases in electron-donating ability (EDA) values of bound phenolic extracts in samples containing AJC compared to the control sample $(\mathrm{p}<0.05)$. The EDA increased as ABTS values increased, and these values increased significantly with increasing concentration of AJC ( $<<0.05)$, showing that higher concentrations of AJC in the sample resulted in higher antioxidant potential. Data also showed a positive correlation between the antioxidant capacities of the various samples.

\section{Sensory evaluation}

Color, aroma, taste, texture, and overall acceptance of the control and the AJC-supplemented jellies were evaluated (Table 2). When evaluated by untrained panelists, statistically significant differences in the all tested attributes were detected among samples $(\mathrm{p}<0.05)$. The sensory panelists rated the samples enriched with $22.5 \%$ AJC as having the highest scores for all tested attributes compared to others $(\mathrm{p}<0.05$ ), although there were no significant differences between samples enriched with $22.5 \%$ and $30 \%$ AJC with respect to aroma, taste, or texture attributes. However, further increasing the AJC concentration had undesirable sensorial effects, especially for color and overall acceptance. On a nine-point hedonic scale, $22.5 \%$ AJC samples received mean scores of $6.38-7.10$. It is noteworthy that the mean score of 7.10 was 
for overall acceptance. The $22.5 \%$ AJC sample received the highest overall acceptance score and therefore seems satisfactory.

As mentioned previously, apricots have a high potential usage as a functional ingredient in the food processing industry rather than only being directly consumed. As the demand for convenient foods such as jelly is rising steadily, the development of AJC-supplemented jellies is a valuable alternative to increase the overall consumption of apricots which may have positive human health effects. Based on our study, jelly containing $22.5 \%$ AJC is recommended for developing AJC-added jellies with improved overall qualities without sacrificing consumer acceptability.

Table 2. Sensory findings of jelly incorporated with different concentrations of apricot juice concentrate (AJC)

\begin{tabular}{cccccc}
\hline \multirow{2}{*}{ Attribute } & \multicolumn{5}{c}{ AJC $(\%)$} \\
\cline { 2 - 6 } & 0 & 7.5 & 15 & 22.5 & 30 \\
\hline Color & $6.76 \pm 2.01^{\mathrm{a}}$ & $5.44 \pm 2.00^{\mathrm{b}}$ & $6.28 \pm 1.67^{\mathrm{a}}$ & $6.38 \pm 1.92^{\mathrm{a}}$ & $4.92 \pm 2.47^{\mathrm{b}}$ \\
Aroma & $3.84 \pm 1.48^{\mathrm{d}}$ & $5.02 \pm 1.63^{\mathrm{c}}$ & $5.78 \pm 1.76^{\mathrm{b}}$ & $6.88 \pm 1.69^{\mathrm{a}}$ & $6.84 \pm 2.12^{\mathrm{a}}$ \\
Taste & $2.98 \pm 1.87^{\mathrm{d}}$ & $4.74 \pm 1.84^{\mathrm{c}}$ & $5.78 \pm 1.63^{\mathrm{b}}$ & $6.88 \pm 2.16^{\mathrm{a}}$ & $6.72 \pm 2.11^{\mathrm{a}}$ \\
Texture & $5.26 \pm 2.66^{\mathrm{b}}$ & $5.66 \pm 1.67^{\mathrm{ab}}$ & $5.58 \pm 1.68^{\mathrm{ab}}$ & $6.40 \pm 1.85^{\mathrm{a}}$ & $6.20 \pm 2.59^{\mathrm{a}}$ \\
Overall acceptance & $3.48 \pm 1.93^{\mathrm{d}}$ & $5.10 \pm 1.80^{\mathrm{c}}$ & $5.66 \pm 1.52^{\mathrm{bc}}$ & $7.10 \pm 1.93^{\mathrm{a}}$ & $6.12 \pm 2.19^{\mathrm{b}}$ \\
\hline
\end{tabular}

Means within the same row without a common letter (a-d) are significantly different $(\mathrm{p}<0.05)$.

\section{Acknowledgements}

This research was supported by the Daegu University Research Grant, 2015.

\section{References}

1. Yoo SJ, Kim SH, Jun MS, Oh HT, Choi HJ, Ham SS (2007) Antioxidant, antimutagenic and cytotoxic effects of Prunus armeniaca extracts. Korean J Food Preserv, 14, 220-225

2. Lee YS, Chung HJ (2013) Quality characteristics of muffins supplemented with freeze-dried apricot powder.

J Korean Soc Food Sci Nutr, 42, 957-963

3. Solis-Solis HM, Calderon-Santoyo M, Gutierrez-Martinez P, Schorr-Galindo S, Ragazzo-Sanchez JA (2007) Discrimination of eight varieties of apricot (Prunus armeniaca) by electronic nose, LLE and SPME using GC - MS and multivariate analysis. Sens Actuators B,
$125,415-421$

4. Sartaj A, Tariq M, KashifSarfraz A (2011) Physico-chemical characteristics of apricot (Prunus armeniaca L.) grown in northern areas of Pakistan. Sci Hortic, 130, 386-392

5. Erdogan-Orhan I, Kartal M (2011) Insights into research on phytochemistry and biological activities of Prunus armeniaca L. (apricot). Food Res Int, 44, 1238-1243

6. Seker IT, Ozboy-Ozbas O, Gokbulut I, Ozturk S, Koksel $\mathrm{H}$ (2009) Effects of fiber-rich apple and apricot powders on cookie quality. Food Sci Biotechnol, 18, 948-953

7. Lee SJ, Chung ES, Park GS (2006) Quality characteristics of tofu coagulated by apricot juice. Korean J Food Cookery Sci, 22, 825-831

8. Shin YJ, Park GS (2006) Quality characteristics of apricot sulgidduk with different addition amounts of apricot juice. Korean J Food Cookery Sci, 22, 882-889

9. Choi WS, Choi MK, Chae KY (2011) Quality characteristics of sulgidduk by the addition of apricot seed powder. Korean J Food Cookery Sci, 27, 653-659

10. Choi WS, Chae KY (2012) Quality characteristics of sulgidduk by the addition of apricot paste. Korean J Food Cookery Sci, 28, 695-701

11. Park KA, Jung HS, Yoon HH (2016) Quality characteristics of haengbyeong using dry rice flour added with raw apricot juice and steamed apricot juice. Culin Sci Hospit Res, 22, 24-36

12. Joo N, Lee SM, Jeong HS (2009) Optimization of jelly made with Rubus coreanus (Bokbunja) using response surface methodology. J Food Sci Nutr, 14, 148-155

13. Cha MJ, Lee JH (2018) Quality and antioxidant properties of jelly incorporated with corn concentrate. Korean J Food Preserv, 25, 436-440

14. Burey P, Bhandari BR, Rutgers RPG, Halley PJ, Torley PJ (2009) Confectionery gels: A review on formulation, rheological and structural aspects. Int J Food Prop, 12, 176-210

15. Delgado P, Banon S (2017) Effects of replacing starch by inulin on the physicochemical, texture and sensory characteristics of gummy jellies. CyTA-J Food, 16, 1-10

16. Chosun media. Jelly, getting rid of gum. Available from: http://biz.chosun.com. Accessed Apr. 26, 2019.

17. Kim AJ, Lim HJ, Kang SJ (2010) Quality characteristics of black ginseng jelly. Korean J Food Nutr, 23, 196-202

18. Kim NY, Jang HK, Yang KH, Lee KJ, Kim MR (2011) Antioxidant activities and quality characteristics of jelly added Rehmannia radix Preparata concentrate. J East 
Asian Soc Dietary Life, 21, 814-822

19. Choi EJ, Lee JH (2013) Quality and antioxidant properties of jelly incorporated with purple sweet potato concentrate. Korean J Food Sci Technol, 45, 47-52

20. Lee JH, Ji YJ (2015) Quality and antioxidant properties of gelatin jelly incorporated with cranberry concentrate. J Korean Soc Food Sci Nutr, 44, 1100-1103

21. Brand-Williams W, Cuvelier ME, Berset C (1995) Use of a free radical method to evaluate antioxidant activity. LWT-Food Sci Technol, 28, 25-30

22. Re R, Pellegrini N, Proteggente A, Pannala A, Yang M, Rice-Evans C (1999) Antioxidant activity applying an improved ABTS radical cation decolorization assay. Free Radical Bio Med, 26, 1231-1237
23. Choi JE, Lee JH (2014) Quality and antioxidant property of gelatin jelly incorporated with jujube concentrate. Food Eng Prog, 18, 65-69

24. Moon JN, Lee SW, Moon HK, Yoon SJ, Lee WY, Lee S, Kim GY (2011) Quality characteristics of chunma (Gastrodia elata Blume) jelly with added Gastrodia elata Blume concentrate. Korean J Food Cookery Sci, 27, 545-556 